\section{História da Parturição no Brasil, Século XIX}

\author{
Anayansi Correa Brenes*
}

A presente pesquisa objetivou resgatar as particularidades da constituição da Arte Obstétrica no Brasil do século XIX, quando, por edital de Dom João VI, é inclulda nas disciplinas que inauguram as escolas de medicina e cirurgia, na Bahia e Rio de Janeiro, em 1808.

Para realizar a pesquisa foram revistas 83 teses médicas obstétricas - produzidas tanto na Bahia quanto no Rio de Janeiro - no século XIX. Verificou-se que, tradicionalmente, esta Arte era realizada por mulheres denominadas "aparadeiras" ou "comadres", que assistiam as mulheres, seja no trabalho de parto e nos cuidados pré e pós-parto, quanto em outras circunstâncias, tais como doenças venéreas e abortos;

A entrada dos médicos-parteiros nesta prática inaugurou, não só o esquadrinhamento do corpo feminino, como a produção de um saber anatômico e fisiologico da mulher, a partir do olhar masculino.

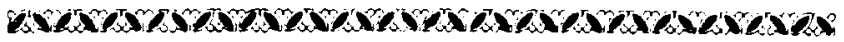

Tradicionalmente, os partos e seus cuidados eram realizados por mulheres conhecidas popularmente como aparadeiras, comadres ou mesmo de parteiras-leigas. Estas detinham um saber empirico e assistiam domiciliarmente as mulheres durante a gestaçäo, parto e puerpério (como também nos cuidados com o recém-nascido). Estas mulheres eram de inteira confiança do mulherio e eram consultadas sobre temas vários, como cuidados com o corpo, doenças venéreas, praticavam o aborto ou mesmo colaboravam com o infanticídio.

Na sua maioria, eram mulatas ou brancas e portuguesas e pertenciam aos setores populares.

A medicina, enquanto instituiçăo, incorporou esta prática (Tosi, 1988) como uma das suas atribuiçōes, intitulando-a Arte Obstétrica e denominou de parteiro ou médico-parteiro os profissionais por ela formados. Historicamente, este processo se deu primeiro na Europa (nos séculos XVII e XVII) se estendendo ao Brasil, ao se inaugurar as escolas de medicina e cirurgia na Bahia e Rio de Janeiro, em 1808.

A introdução da medicina neste espaço inaugurou não só a experimentação clínica articulada com o discurso anátomo-patológico, quanto produz um discurso

Cademos de Saúde Páblica, RJ, 7 (2): 135-149, abr/jun, 1991
*Professora do Departamento de Medicina Preventiva e Social da Faculdade de Medictna da UF MG. Coordenadora do Nho cleo Sande da Mulher do $D M P S / F M / U F M G$. 
a partir da penetraçåo da figura masculina no saber e prática obstétrica.

Desde o momento da sua constituição, esta arte centra seus estudos no parto (posteriormente sobre a gravidez) dentro do enfoque biológico, por forte influência da anatomia patológica. $O$ discurso anátomo-patológico permitia a interrupção da gravidez, pelo parteiro (ou médico-parteiro) desde que algum sinal anatômico indicasse risco de vida para a mulher. Podemos apreciar este fato nas falas de médicos (parteiros), onde o aborto $\varepsilon$ indicado diante de vícios de conformação da bacia congênita ou adquiridos (raquitismo, osteomalácia); hidropesias excessivas de omnios; deslocação irredutível do útero; ruptura uterina; hemorragias uterinas rebeldes; aneurisma aórtico; lesōes orgânicas do pulmão; hydiopericárdio; hydrotórax; alienação mental; vômitos rebeldes; vícios que diminuem o diâmetro da bacia.

Paralelamente à construção do discurso anátomo-patológico, processou-se um sincretismo a nível da terapêtutica. Este deu-se com as práticas populares das curiosas, quanto com a medicina das fisicaturas, não sem antes criticar e experimentar (em particular a prática das curiosas), como é o caso do uso do Centeio Espigado, onde o médico-parteiro, Madame Durocher, critica o conhecimento das "comadres" sobre o centeio e o uso que as mesmas fazem dele nos trabalhos de aborto (Durocher, 1887).

Assim, a prática obstétrica do período incorporou técnicas das curiosas e das fisicaturas que eram utilizadas para a interrupção de uma gravidez. Estes métodos abortivos foram denominados de primeira classe:

1 - Centeio espigado

2 - Sangria

3 - Aplicação de sanguessugas (sugar a parte intema das coxas ou mesmo da vulva)

4 - Purgativos

5 - Diuréticos

6 - Excitantes (por exemplo, preparaçăo de canelas)

7 - Eletro galvanismo

Em todas as teses defendidas pela obstetrícia nas escolas de medicina, salvar a vida da mulher era o objetivo fundamental. A este respeito o Dr. Ermínio Cézar Coutinho, da Faculdade de Medicina da Bahia, em novembro de 1858 , defendendo teses sobre "Quais as circunstâncias que justificam a provocação ao aborto", o autor indica que o aborto que possa vir colocar em risco de vida a mulher deve ser completamente rejeitado (refere-se aos casos em que a mulher esteja muito fraca e haja impedimento anatômico à prenhez - Coutinho, 1858). Para estas situações recomendamse as técnicas usadas nos casos da bacia estreita: tais como os métodos de hysterotomia, symphysiotomia, 
embryotomia, antes do termo da gravidez. Apesar de compreender que a symphysiotomia e a craniotomia deviam ser condenados porque colocam em perigo a vida da mulher (Coutinho, 1858), e a cesariana ser um crime porque quase sempre era fatal para a mulher, - aborto, segundo este autor, deveria ser praticado (Coutinho, 1858) nos casos em que não existissem vícios de conformaçãa da bacia.

Mesmo antes de dominar técnicas como o fórceps e a cesariana com sucesso para a mulher e a criança durante o parto, a obstetrícia proclama a sua exclusividade desde 1840. Também a partir deste perfodo, percebe-se o deslocamento do seu olhar para questöes tais como sexualidade, higiene e moral feminina.

Assim, a partir da segunda metade do século XIX, a medicina se articula a outras instâncias do social na produção de uma nova imagem sobre a mulher, da relação desta com os filhos e sobre seu papel em sociedade, esposa-mãe-dona-de-casa.

Vejamos aspectos deste processo e suas implicaçōes na constituição desta disciplina:

\section{A IMPLANTAÇĀO DAS ESCOLAS DE MEDICINA}

Com a chegada da Corte Portuguesa no Brasil, em 1808, ocorreu a implantação do ensino oficial de Medicina. A primeira escola foi implantada na Bahia e decorreu de um pedido do Barāo de Goyana - José Correia Picanço - que falou a D. João VI da necessidade de se criar um colégio de cirurgia. Este concordou com a idéia e, em Carta Régia de 18 de fevereiro de 1808, assinada por D. Femando José de Portugal, Ministro do Reino, foi determinado que Picanço fizesse o plano do curso e que escolhesse entre os cirurgiỏes do Hospital Militar os professores que deveriam ensinar não só Cirurgia, mas também Anatomia e Arte Obstétrica (Souza, 1967).

A segunda escola a ser autorizada por D. João VI foi a do Rio de Janeiro; isso se deu devido à sua mudança para lá no mês de fevereiro de 1808 . Entre as várias medidas administrativas importantes tomadas por ele estava o ensino médico. Pelo decreto de 5 de novembro de 1808 criou-se a Escola de Cirurgia do Rio de Janeiro e, em 25 de janeiro de 1809 , foi nomeado para lesionar Medicina Operatória e Arte Obstétrica, Joaquim da Rocha Mazarem. O currículo desta escola era mais amplo do que o da Bahia, precisando de sede maior; por isso a escola foi mudada do Real Hospital Militar de Ultramar para a Santa Casa (Briquet, 1971).

\section{ESTRUTURAÇÃO DO ENSINO MÉDICO}

Para a matrícula do aluno em ambas as escolas bastava apenas que 0 candidato soubesse ler e escrever. 
Recomendava-se apenas: Bom será que entendam as linguas inglesa, francesa etc., dal haver passado à história com o nome de "Regime de "Bom Será" (Salles, 1971).

O curso durava quatro anos, e ao final do quarto ano os alunos tiravam uma certidão de que estavam prontos para fazer o exame final perante o Físico-Mor. Uma vez aprovados, prestavam juramento aos Santos Evangélicos, de dignamente exercerem a nobilíssima profissão. Podiam curar onde não houvesse médicos.

O alvará de 7 de janeiro de 1809 concedeu ao Cirurgião-Mor, Picanço, autoridade para conferir diploma de médico ou cirurgiảo no Brasil, a quem prestasse exame perante Junta por ele nomeada.

A primeira reforma desse ensino ocorreu após o decreto de 26 de fevereiro de 1812 , que nomeou o médico baiano Manuel Luiz Álvares de Carvalho Diretor dos Estudos Médicos e Cirúrgicos da Corte e dos Estados. Considerando precários os meios com que eram dotados os colégios, aquela autoridade ampliou os cursos para cinco anos, criou novas cadeiras e deu certa autonomia às congregaçōes.

Após o quinto ano, os cirurgiōes formados gozavam das seguintes prerrogativas: seriam preferidos em todos os partidos públicos aos que não tivessem esta condecoração; poderiam, em virtude de suas Cartas, curar todas as enfermidades onde não houvesse medicos; seriam, desde logo, membros do Colégio Cirúrgico; poderiam, todos aqueles que se enriquecessem de princípios e práticas a ponto de fazer exames que aos médicos se determinavam, chegar a ter faculdade $\mathrm{e}$ grau de Doutor em Medicina.

Até 1815, o ensino na Bahia continuava como antes, lecionavam-se apenas Cirurgia e Anatomia e, apesar da resolução de D. João VI, que ordenava o ensino da Arte Obstétrica, Picanço năo fez qualquer referência à Obstetrícia até essa data. O plano de estudos feito por Dr. Manuel Luiz Álvares de Carvalho é implantado na Bahia em 17 de março de 1816. Neste ano, a instalação da escola passa para a Santa Casa. No novo currículo constava que, para o quarto ano, o Prof. Manuel da Silveira Rodrigues lecionaria Instruçōes Cirúrgicas e Obstetrícia e, no quinto ano, José Avelino Barbosa ensinaria Medicina Prática e Obstetrícia.

Com essa reforma, o curso de Obstetrícia, na Bahia, só tem início em 1818, já que os alunos matriculados sob este novo regime só atingiram o quarto ano do curso nesse ano. O curso, inicialmente, foi meramente especulativo e abstrato, pois a escola carecia de uma enfermaria ou serviço clínico para mulheres grávidas e parturientes em que se pudesse fazer 0 ensino prático da matéria lecionada. 
No Rio de Janeiro, com a reforma realizada por Álvares de Carvalho, passa a lecionar Operaçōes e Arte Obstétrica, Manuel Álvares da Costa Barreto.

A formação de profissionais da Medicina no Brasil funcionou precariamente nos primeiros anos do século XIX, pois em meio a agitação política de várias ordens, que determinava a Proclamação da Independência, depois da abdicação do primeiro Imperador e a falta de paz interna, acabaram relegando a segundo plano quaisquer medidas de aprimoramento do ensino. Nestes anos estabeleceu-se acentuada má vontade entre médicos portugueses e brasileiros; aqueles, queriam que apenas valessem os diplomas expedidos em Coimbra. Porém, em 9 de setembro de 1826, foi outorgado explicitamente às Escolas Nacionais, o direito de conferir cartas de cirurgião ou de cirurgiâo formado aos alunos por elas diplomados (Salles, 1971).

A denominação de dois estabelecimentos oficiais de ensino foi uniformizada para Academia Médico Cirúrgica (da Bahia ou do Rio de Janeiro, conforme o caso), e com prestígio crescente apesar das falhas notadas. A constatação dessas falhas motivou mudanças radicais que foram introduzidas e consubstanciadas num antiprojeto de reforma que foi aprovado pela Câmara em 3 de outubro de 1832. Essa reforma assinala notável progresso nos métodos de ensino. Nela, os estabelecimentos passaram a ter organizaçăo idêntica e a mesma denominação; o curso médico passou a ser feito em seis anos e abrangia 14 cadeiras, regidas por igual número de lentes.

As faculdades passaram a conceder os títulos de doutor em Medicina, de farmacêutico e de parteira, sem os quais ninguém podia exercer atividades em qualquer dos ramos da arte de curar.

A duração do curso de Farmácia era de três anos, e a arte obstétrica era ensinada pelo titular da décima cadeira (partos, moléstias de mulheres pejadas e paridas, e de meninos recém-nascidos).

Outra mudança que ocorreu com esta Lei de 1832 foi a obrigatoriedade dos exames preparatórios. Para os candidatos à Medicina, exigiam-se Francês, Inglês, Latim, Filosofia, Aritmética e Geometria. Para Farmácia, os mesmos preparatórios menos Latim e Filosofia.

E em 1832 que tem iń́cio o ensino oficial de Obstetrícia para mulheres, nas duas primeiras faculdades médicas. Na do Rio de Janeiro, diplomou-se em 1834 a mais célebre das parteiras, francesa de nascimento, Maria Josefina Matilde Durocher (1808-93), que era conhecida como Madame Durocher. Foi a primeira mulher a ser recebida, como membro titular, na Academia Imperial de Medicina, em 1871. Madame Durocher vestia-se como homem porque, explicava, exercia uma profissão masculina (Souza, 1967). 


\section{A EVOLUÇĀO DAS ESCOLAS}

A reforma promovida em 1832 fez com que o ensino teórico melhorasse bastante, porém ficou ainda deficiente a parte prática do curso. No Rio de Janeiro, - curso era ministrado em dois locais, no Hospital Militar e na Santa Casa. Ficou assim até 1884. Na Bahia a faculdade voltou a localizar-se mais uma vez no velho prédio do Colégio dos Jesuítas e ocupava 12 casas que formavam o lado esquerdo da Rua das Portas do Carmo, além de utilizaruse das enfermarias da Santa Casa.

As dificuldades materiais persistiam, e, para disfarçar tais dificuldades, Leôncio de Carvalho, no Rio de Janeiro, em 1879, faz uma reforma onde introduz a frequêencia livre, a matrícula de mulheres no curso médico e o funcionamento do curso em locais estranhos à faculdade.

Quando Vicente Cândido de Figueiredo Sabóia assume a Direção da Faculdade do Rio de Janeiro (de 1882 a 1889), ele consegue, através de recursos particulares, reformar e ampliar as instalaçöes desta. Também reforma o curficulo que passa a contar com 26 cadeiras, sendo a de Ginecologia e Obstetrícia regida por Érico Coelho. Porém, a Obstetrícia continuava com problemas, pois a sua instalação na Santa Casa era impedida pelas Irmãs de Caridade que consideravam o parto uma falta de pudor, e somente a interferência direta do provedor Ferreira dos Santos conseguiu solucionar o problema. Portanto, $\varepsilon$ sob a administraçäo do Visconde de Sabóia que tem início o verdadeiro ensino prático. O perfodo administrado por Sabóia foi denominado o Perlodo Aureo. Sabbia foi demitido com a Proclamação da República, e o perfodo de 1889 a 1901 foi considerado um período de estagnação,

E importante salientar que, em 1887, forma-se a primeira médica no Brasil, a Drt: Rita Lobato Velho Lopes, que fez curso na Faculdade da Bahia. No Rio de Janeiro, a primeira mulher a se formar, e segunda no Brasil, foi a Dr: Ermelinda de Vasconcelos, em 1888 (Souza, 1967; Salles, 1971).

\section{AS DIFICULDADES QUE PERSISTIRAM NA ESCOLA BAIANA}

$\mathrm{Na}$ Bahia, com a reforma de 1832 , é extinto o Hospital Militar, mudando-se o hospital e a escola para a Santa Casa. A mudança realmente ocorreu em 2 de julho de 1833 e as aulas de clínica iniciaram em agosto deste mesmo ano. Porem, neste novo hospital, não havia uma enfermaria particular que pudesse ser dada à escola para a intemação de mulheres, fican- 
do à disposiçāo da escola um lado inteiro de uma enfermaria para os professores colocarem as pacientes de clf́nica e cirurgia. As condiçōes de ensino das clínicas eram as mais precárias, tomando-se mesmo impossível fazerem-se trabalhos práticos de clf́nica obstétrica. Nota-se, portanto, que a reforma de 1832 , também na Bahia, só melhorou o ensino teórico, ficando ainda a escola, por muitos anos, sem uma enfermaria ou serviço clínico para mulheres grávidas ou parturientes.

Em 1854, o professor Malaquias Álvares dos Santos faz o seguinte relato da cadeira que ocupa:

No ensino da Obstetricia e da Medicina Operatoria, é então de tal modo sensivel nesta escola a falta em que nos tem deixado ficar na respectiva clínica, que nem sei como possamos convenientemente ter fé nos conhecimentos que possam ter nossos alunos (Souza, 1967).

$O$ professor Domingos Rodrigues Seixas, em 1862, lamenta que a parte prática do curso não pode ser congruentemente desempenhada por falta de parturientes em que se exerçam as manobras.

O professor Matias Moreira Sampaio, ao redigir a Memória Histórica de 1867, diz o seguinte:

Embora o obscuro professor, que nesta hora prende a vossa atenção, empregue no desempenho de seus deveres o esforço que permitem sua fraca inteligência e limitado entendimento, o ensino de partos está longe da perfeiçâo pela falta da clinica respectiva, de modo que podemos dizer que, salvo algumas manobras exercidas no manequim, fazemos somente partos teóricos (Souza, 1967).

Em 1873, para o autor da Memória deste ano, o professor Matias Sampaio assim se expressou:

Animado pelo mais ardente desejo, e sem ter arrefecido ainda na carreira do ensino, empenho todo o esforço de que disponho para que os estudantes se habilitem na arte de partejar; apesar do meu emperiho, confesso que apenas eles adquirem conhecimentos teóricos por nos faltar ainda o ensino prático, falta sentida e contra a qual têm reclamadı quase todos, senão todos os historiadores de ambas as Faculdades de Medicina do Império. Entretanto, tenho fé que um dia virá em que semelhante falta desaparecerá, dotandonos o governo Imperial ao menos com uma pequena sala, onde sejam recebidas as parturientes (Souza, 1967).

O Hospital da Santa Casa de Misericórdia, local onde funcionavam as cadeiras de Clínica, não tinha condiçōes que pemitissem a prática obstétrica, ficando o ensino nesta situação por 60 anos, quando em 1875. 
se instala no Hospital de São Cristovão uma enfermaria de partos, sendo professor da cadeira, o Barảo de Itapoā.

O professor Luiz Álvares dos Santos, historiador da escola, em 1876 narra o seguinte:

A provedoria da Misericórdia abriu no ano passado, em uma sala de seu hospital, uma enfermaria de partos que, muito bem inspirada, entregou à direção do nosso nobre colega, o digno Professor de Parto, o Senhor Barẫo de Itapoá. Pois bem, apesar do fanatismo que parece querer fechar as salas da clinica d̀s parturientes, o ensino vai dando útil resultado, pelo que nos cabe animar aquela reforma, importante em todos os sentidos. Houve três parturientes. Os estudantes e os médicos tiveram ocasiâo de ver durante o ano aqui muitas operaçōes de obstetrlcia (Souza, 1967).

Somente algumas pacientes procuravam os serviços da clínica, já que havia uma resistência por parte do público contra a enfermaria de partos; essa objeção permaneceria, ainda, por muitos anos sob a forma de receio que as parturientes manifestavam ao internamento (Souza, 1967).

Apesar dos beneffcios trazidos para o ensino dessa nova enfermaria de partos, a prática escolar da tocologia deixava, ainda, muito a desejar, pois o serviço clínico na enfermaria de partos, como também de muitas outras, era incompleto e defeituoso; as instalaçōes das enfermarias eram precárias; havia um déficit de aparelhagem e era reduzidfssimo o número de mulheres grávidas que procuravam o serviço de objeto às funçōes letivas. Essa situação perdurou por muitos anos.

Há uma nova reforma do ensino, que se inicia em 1879 e termina em 1894, criando a cadeira de Clínica Obstétrica e Ginecológica. Essa nova cadeira continuava a funcionar na mesma enfermaria Santa Izabel do Hospital São Cristovão, tendo como professor Climério de Oliveira, que tomou posse em 1885 (Souza, 1967).

Os primeiros anos de ensino, após a posse de Climério de Oliveira, continuavam como os anteriores. Em 1892, ele envia uma carta ao professor Luiz Anselmo da Fonseca, cronista da Faculdade em 1891, fazendo os seguintes pronunciamentos a respeito do seu serviço clínico, que ainda funcionava no velho Hospital da Misericórdia:

O curso de Cllnica Obstétrica e Ginecológica teve a regularidade posstvel, atenta às péssimas $e$ precárias condiçôes em que se acha instalado no Hospital de Caridade, instalaçōes contra as quais tenho sempre protestado, já na Memória Histórica que redigi, já nos programas dos cursos, nas preleções, na Congregação. No terceiro 
Congresso Médico Brasileiro, tive a ocasiāo de assim enunciar-me: quem conhece o hospital em que funcionavam as clfnicas desta Faculdade, a situação de suas enfermarias, a disposição de seus cômodos, o acúmulo de seus leitos, a distribuição de seus serviços clenicos, a sua ventilação, a construçâo de seus esgotos; quem ali respira fétidos odores e doentios ares e conhece, pelo que leu ou pelo que viu, qual o conjunto de circunstâncias que devem tornar saudável um estabelecimento dessa ordem; nâo pode deixar, sob o ponto de vista das grandes intervençōes cirúrgicas, de considerá-la um foco de letalidade, ao invés de um meio de restabelecimento da saúde. Conseguintemente, quem assume a responsabilidade de um serviço clínico de cirurgia geral ou especial como esse por exemplo, que tenho a honra de dirigir, que tem por função a maternidade, ligado, portanto, a um triplice compromisso: com a humanidade, de zelar por suas vidas; com a pátria, de garantir-lhe o cidadâo nascente; com a ciência, de fazer valer os seus princtpios $e$ os seus preceitos - $e$ tudo isso num cubiculo infecto, encravado entre boas e más enfermarias e as latrinas do hospital, servindo por enfermarias comuns às salas de Medicina e Cirurgia (...) e não tem, senhores, diante de si uma estatistica de luto, mas plenamente animadora, näo pode calar aplausos aos propignadores dos métodos antissépticos (...) e deixar de render um preito de homenagem ao talento cintilante de Lister, que produziu em uma de suas mais brilhantes fulgurações este vigente recurso que abriga a vida do doente, amplia as esperanças da cirurgia, aureola a ciência com os mais fúlgidos louros das mais transcendentes conquistas (Souza, 1967).

Esta nova enfermaria com funcionamento precário durou 18 anos, e somente com a mudança do Hospital da Santa Casa de Misericórdia para as instalaçōes no Bairro de Nazaré $\varepsilon$ que houve melhora. Neste novo hospital havia uma enfermaria destinada à clínica de partos e, nesta mesma enfermaria, funcionava, também, a clínica ginecológica e a pediátrica.

Apesar da ampliaçẫo do curso, do número crescente das gestantes que procuravam a clínica, da maior freqüência dos alunos e do melhor aproveitamento destes, o professor Climério de Oliveira ainda năo estava satisfeito com o Hospital de Santa Isabel e desejava fundar uma matemidade anexa à Faculdade de Medicina.

A idéia de criar maternidades anexas às Faculdades de Medicina vinha desde a Lei de 28 de abril 
de 1854 , que reformou as faculdades e determinava a criação das maternidades; porḱm, somente 40 anos após essa lei começaram oficialmente, na Bahia, os trabalhos para construção da maternidade. $O$ professor Paclfico Pereira foi quem deu o primeiro impulso, ao procurar o professor Manuel Vitorino, Senador Federal, e solicitar a influência deste para que fosse incluída na lei de orçamento da Uniāo para 1894 uma verba a ser aplicada na construçōa. Novas verbas foram votadas nos anos seguintes; com isso, a Santa Casa foi juntando os contos concedidos pelo Governo Federal para a fundação do aludido estabelecimento.

Nove anos depois, em 1903, o professor Alfredo Brito, então diretor da Faculdade, celebrou um contrato com a Santa Casa e aprovado pel governo da Uniäo para a construção dos pavilhões necessários para o serviço de clínica obstétrica.

$\mathrm{O}$ professor Climério de Oliveira forneceu à Secretaria da Agricultura os dados para a organizaçã da planta e, em 26 de abril de 1903, depois de aprovada pelo poder competente, a obra foi contratada. No dia 3 de outubro deste mesmo ano foi colocada a primeira pedra.

As verbas que o Governo Federal forneciam eram insuficientes, então Climério lançou uma campanha para ajudar a construçāo. Formou um Comitê de Senhoras da Sociedade Baiana; este realizou espetáculos no Teatro Politeama, com renda destinada à construçẩo. O espetáculo era o drama $A$ Maternidade, escrito pelo professor Climério de Oliveira.

O Governo Federal e a Prefeitura também contribufram, ficando a obra pronta cinco anos depois de iniciada e levou, ainda, algum tempo com retoques finais e aparelhamento, sendo inaugurada em 30 de outubro de 1910.

Após a inauguração, o curso de Obstetrícia passou a ser feito na Maternidade, por estar separado em duas cadeiras de Clínica Ginecologica e Obstetrícia (Souza, 1967).

\section{MULHERES: ANATOMIA É DESTINO VENHAM SE CONSULTAR CONOSCO}

Está posto novamente o problema do corpo. Aos médicos cabia alcançar dois objetivos: um local para observação do corpo - a clínica de partos, a matemidade, o hospital junto à escola. Inúmeras vezes os médicos reclamaram sobre a falta de prática durante o curso, especialmente na área obstétrica, a falta de uma clínica de partos junto às escolas. O segundo objetivo a ser alcançado pelos médicos é o que nos interessa mais nesse momento, ou seja, conseguir trazer à clínica, ao hospital, ao consultório a mulher ou, também, pode-se dizer, o corpo feminino. 
Conforme procuramos demonstrar no tópico anterior, houve todo um esforço por parte da corporação médica em construir uma imagem do médico que inspirasse confiança na população. Porém, isto ainda foi pouco para conseguir levar as mulheres à presença do obstetra e muito menos, ainda, para convencê-las e se abrirem para eles. A partir desta problemática, o discurso médico criou como que um "jogo" com a população feminina do Brasil Império. Jogo, porque, por um lado, o discurso médico, em harmonia com os demais discursos presentes no momento, utilizando as estratégias que lhe eram permitidas pelas circunstâncias, forjou para a mulher uma nova subjetividade, que, entre as alteraçōes imediatas que possibilitou à esta, garantiu-lhe um novo papel na sociedade, abrindo-1he as portas para uma vida social mais intensa, esboçando-1he nova configuração dentro do lar, da familia, tornando-a, enfim, um ser bem mais vivo que a mulher da sociedade patriarcal da colônia. Porém, o ponto de apoio deste discurso que criou a mulher da sociedade imperial foi a sexualidade feminina. Sexualidade que foi descrita a fundo, com acurada precisão fazendo a mulher um ser frágil e inconstante, a quem somente os médicos poderiam orientar, por serem os únicos que a conheciam. Deste "jogo" surgiram "o mito do amor materno", a "mãe dedicada", "boa esposa", "a rainha do lar", as histéricas, as mundanas e toda uma série de tipos femininos que ocupariam a literatura médica e o imaginário social do século XIX. A mulher criada no século XIX, que povoou as páginas do romance nacional, destacava-se pela sua constituição frágil e débil. Em geral, as mulheres são muito mais delicadas, mais ternas, mais sensiveis, mais pactficas, mais de formar coraçöes e conduzi-los que o homem (Nunes, 1846). Foram criadas para ser esposas e mães. Todos os órgãos são delicados, flexiveis, fácil de excitar e ferir, suscettveis em todos os sentidos (Nunes, 1846). Os médicos não se limitavam a afirmações genéricas, onde exploravam aspectos psicológicos das mulheres. Seu discurso trazia observações que só poderiam se pautar sobre uma sólida observação, observação que the garantia o rigor científico e a posse da verdade.

Voltemos às :eses para exemplificarmos este processo. Com relação ao tratamento dispensado às mulheres em época anterior, näo havia o tratamento das moléstias das mulheres, antes por ignorância do que por causa dos "preceitos" e assim, as mulheres padeciam e que, a função de melhorar a vida, curar, que nestes casos cabia ao padre não era dispensado ao sexo feminino (Nunes, 1846). O discurso médico "criava" os tipos, mostrava claramente suas características, o tratamento apropriado, caso fosse um tipo patológi-

Cadernos de Saúde Pública, RJ, 7 (2): 135-149, abr/jun, 1991 
co, mas isto, é preciso ressaltar, colocava-os sempre sob sua tutela ou, pelo menos, exigia participação nas decisões tomadas por outras instituiçöes responsáveis pelo controle populacional.

Vê-se aqui, apesar de ser um caso extremo, a internação das histerricas, como os médicos deram importância à internação e à educação, desde que orientada por eles. Ainda intervindo pela mulher acometida por alguma espécie de patologia, temos o seguinte relato a respeito das alteraçōes no psiquismo que estes estados acarretam: É curioso apreciar como simples perturbações orgânicas, dada sua repercussão no psiquismo, podem assim contribuir indiretamente, no determinismo do crime (Da Silveira, 1926). O processo menstrual pode acarretar desde excitabilidade nervosa exagerada e modificaçôes do humor, até as impulsōes às vezes irresistlveis e verdadeiras psicoses que têm como causa uma auto-intoxicação genital (Da Silveira, 1926). Alto valor em medicina legal assumem as perturbaçöes psíquicas em mulheres puérperas. Os crimes de infanticidio são na maioria dos casos cometidos num estado patológico de inconsciência (Da Silveira, 1926). Vê-se, então, que as mulheres poderiam contar com a defesa dos médicos, desde que levassem a eles seus problemas e suas confidências. Com relação à educação da mulher, destacamos o seguinte trecho: Com um tal sistema de educação que não prepara a moça para as responsabilidades da vida, que ela vincula sobre a humanidade conseqüências medonhas que não escapam mesmo a um observador pouco escrupuloso, urge que o corpo médico ciente dos efeitos de uma educação que exclue toda a noção de fisiologia, erga a voz em favor da reforma do ensino público, porque segundo Balzac e repetido por Pestalozzi, "le future des nations repose sur l'education des mères de famille" (Rennotte, 1895).

Inúmeras foram as técnicas empregadas para atrair o público feminino aos locais de internamento. É difícil datarmos, através da leitura das teses, o momento em que esta atração passou a se efetuar de maneira satisfatória. O que podemos perceber é que, apesar de atenderem ao chamado médico, as mulheres viam a clínica como um local ao qual deveriam acorrer num momento de grande necessidade, desconsiderando, porem, a continuidade do tratamento. Isto em muito dificultou o trabalho médico, pois a eles interessava a permanência das mulheres na clínica para observação e testes.

Mas, tendo em vista a necessidade da presença das mulheres na clínica, especialmente na maternidade, pois para médicos e estudantes este seria o único meio de adquirir a prática na difícil arte de partos (Fonseca, 1933), os médicos tentaram em decorrência da não-cor- 
respondência das mulheres aos seus apelos, conseguir o apoio do governo no que conceme aos processos de intemação, controle e cadastramento nas clínicas existentes no Império.

Há uma séria objeção ao estabelecimento desta clinica que é a falta de parturientes, que de certo modo haveria com a organização atual; mas se o governo quiser tomar as devidas providências não somente abundarão as parturientes, mas obterá aumento da população, perfeito conhecimento dos nascimentos e evitará os infanticldios que se dão em grande número no Rio de Janeiro. Para este fim dever-se-á obrigar a toda e qualquer mulher rica ou pobre que tiver parido a levar ou mandar levar o recém-nascido à apresentaçâo em casa do subdelegado do distrito; este não deve ser qualquer cidadão indistintamente, mas um empregado proprio do governo. A pessoa encarregada de apresentar a criança o fará em um livro apropriado o dia e hora do nascimento da mesma, bem como o nome que se the deu ou o que se lhe deseja dar, o sexo, os defeitos, etc., etc.; escreverá o nome da mâe, do pai (se for declarável), a sua morada, o estado em que vivem, a profissão, etc., etc.. Depois deste ato dará um bilhete declarando ter sido apresentada a criança ...., nascida no dia .... filha de .... moradora na rua ... número ... . Rigor excessivo, rigor na execução destas medidas; e para isto deve-se dar maior publicidade a estas leis.

Com a necessária vigilância poder-se-å punir os infantictdios que ainda tiverem lugar, $e$ obterse-ä uma lista exata dos nascimentos, o que não se alcança atualmente com o péssimo sistema de confiar aos curas a parte relativa ao nascimento e falecimento da população, pois isto pertence à administração civil e não à igreja.

A mulher pobre, para livrar-se de todos estes incômodos com toda a facilidade, preferirá parir no hospital do que em casa, $e$ as pessoas que hoje acolhem facilmente uma mulher em trabalho de parto deixarão de fazê-lo para furtar-se às "exigências da lei" (Guimarães, 1863).

\section{CONCLUSÃO}

Discursos moralistas e filantrópicos sobre o aleitamento materno, cujas primeiras destinatárias eram as mulheres das familias abastadas, que continuavam possuindo empregadas em função de amas-de-leite. Do abandono infantil, parcialmente explicado pelo desejo egoista e narcisista destas em manter o corpo belo,

Cadernos de Sáde Pública, RJ, 7 (2): 135-149, abr/jun, 1991 
de conservar a forma estética e pelo medo de perder o marido, a exemplo dos aristocratas franceses. Do infanticldio disfarçado pelas comadres (curiosas) bastante adestradas para ocultar o crime ou mesmo das crianças encontradas nos necrotérios ou nas vias públicas ou aquelas lançadas na roda (casa dos expostos) e da prática do aborto realizado pelas mulheres (ou ajudadas por curiosas) acenam para as mulheres (ricas ou pobres, casadas ou solteiras) de vários pontos do social, na intensāo de recluí-la e com isto afastá-la do perigo da prostituição e da perdição, ao menor deslize.

Nessa cruzada, a participação dos médicos foi significante. Os seus discursos sobre a ausência de leis severas que punissem as práticas de aborto e infanticídio vieram de encontro à construção dos dispositivos legais para seu enquadramento criminal, antes mesmo da proclamação da República (Coutinho, 1858). Simultaneamente a este processo, as prescrições médicas de aborto foram sendo reduzidas extremamente ao essencial.

Assim, se no início do século XIX a arte obstétrica priorizava a vida da mulher ao menor sinal de perigo, as "novas" técnicas alcançadas (fórceps e cesariana) possibilitaram que o discurso fosse modificado. Hoje prioriza-se que o processo finalize com uma mãe e filho sadios, apesar do desejo ou não da mulher ou mesmo de uma gravidez que coloque em risco sua saúde e vida.

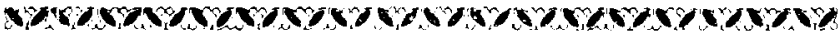

This research aimed at recovering the peculiarities of the development of Obstetrical Art in Brazil during XIX century, starting in 1808, when a legal act signed by $D$. Joâo VI included this discipline in the initial curriculum of the schools of medicine and surgery founded in Bahia and Rio de Janeiro. Research was undertaken through the review of 83 medical theses in the field of Obstetrics, produced in Bahia and Rio de Janeiro in XIX century. The data showed that Obstetrical Art was traditionally performed by women called "aparadeiras" (catchers) or "comadres", who cared for women before, during and after delivery, and provided assistance in other situations, like venereal diseases and abortion. The inclusion of physicians-obstetricians in this practice led not only to a scrutinizing of the female body, but also to the production of an anatomical and physiological knowledge of the female organism from a male standpoint. 


\section{AGRADECIMENTOS}

Este artigo é resultado da pesquisa "História da parturição no Brasil, século XIX", realizada com apoio do $\mathrm{CNPq}$ e do $\mathrm{CPq} / \mathrm{PRPq} / \mathrm{UFMG}$ em 1989. Na ocasião estendo meus agradecimentos aos alunos: Walther Esteves Lima (Medicina); Ulicéia Gonçalves Vilela (Medicina); Maria de Fátima Gomes (História) e Carlos A. Mitrand (História), pelas suas contribuições na realizaçāo da pesquisa como, também, a Míriam Monteiro de Castro (Medicina) na revisão do presente artigo.

Ao professor Antônio Cândido de Melo Carvalho meu eterno agradecimento pela tradução ao inglês do resumo inicial.

E à Mariana Aparecida de Lélis Adão por seu esforço e carinho em datilografar este trabalho.

\section{REFERÊNCIAS BIBLIOGRÁFICAS}

BRIQUET, R. Obstetricia normal. São Paulo, Ed. São Paulo, 1971.

COUTINHO, E.C. "Quais as circunstâncias que justificam a provocação do aborto" (....) "Como reconhecer en que circunstâncias houve o aborto?" Teses apresentadas a Faculdade de Medicina da Bahia em novembro de 1858.

DA SILVEIRA, N. Ensaio sobre a criminalidade da mulher no Brasil. Tese inaugural da Faculdade de Medicina da Bahia, 1926.

DUROCHER, M.M.J.M. Consideraçöes sobre a clfnica obstétrica. Rio de Janeiro, 1887. Ou mesmo Deve ou não haver parteiras? Rio de Janeiro, s.d. Consideraçōes práticas sobre o centeio e a ergotina, Rio de Janeiro, s.d.

FONSECA, O.A.R. Em torno da medicina, Rio de Janeiro, 1933.

GUIMARÄES, A. Breves consideraçōes sobre o estudo e exercício da medicina no Brasil e em França. Doutor em medicina pela Faculdade de Medicina do Rio de Janeiro. Paris, 1863.

NUNES FILHO, R.J. Algumas consideraçöes sobre o homem, especialmente suas relaçōes entre o físico e o moral. Tese apresentada na Faculdade de Medicina da Bahia em 2 de novembro de 1846.

RENNOTTE, M. Influência da educação da mulher sobre a medicina social. Tese apresentada a Faculdade de Medicina e de Farmácia do Rio de Janeiro, 26.03.1895.

SALLES, P. História da medicina no Brasil. Belo Horizonte, Ed.G. Holman, 1971. p. 141-161.

SOUZA FILHO, J.A. $O$ ensino da cltnica obstétrica na Universidade da Bahia. Salvador, Ed. da Universidade Federal da Bahia, 1967.

TOSI, L. A mulher e a ciência. Ciclo de Conferencias proferidas na Faculdade de Medicina - UFMG, em junho/88.

Cadernos de Saude Pública, RJ, 7 (2): 135-149, abr/jun, 1991 